\title{
Tourists and the Seabirds in Galapagos
}

\author{
R.W. Tindle
}

Are the seabird colonies in the Galapagos Islands harmed by the ever increasing numbers of tourists? So far the National Park authorities have been able to safeguard the main nesting grounds from trampling by keeping visitors to prescribed paths, but the birds could be harmed in other ways and these need to be investigated. The author describes the research he is doing to find out the facts. This work has been aided by a grant from the Oryx $100 \%$ Fund.

A frigate bird Fregata magnificens on its nest, apparently undisturbed at the approach of a human, has in fact a soaring heart-rate (Hirsch, in press), as do blackbirds Turdus merula and lapwings Vanellus vanellus in similar circumstances. ${ }^{5}$ In kittiwakes Rissa tridactyla a broken pair-bond results in the bird being unable to form a stable bond with another mate, and thus having a much reduced chance of successful breeding for several years afterwards. ${ }^{1}$ Experiments with laboratory rats indicate a post-partum behavioral influence of mothers on their offspring. Stressed mothers tend to produce stressed offspring, whose status in society may jeopardise their chances of survival and reproduction. ${ }^{4}$

With this sort of background, we must be concerned for the well-being of animal colonies that are frequently visited by human observers, and thus potentially subject to disturbance. In the Galapagos Islands one of the main tourist attractions are the seabird colonies, with waved albatrosses Diomedea irrorata, red-footed, blue-footed and masked boobies Sula sula, $S$. nebouxii and $S$. dactylatra, two species of frigate bird, $F$. magnificens and $F$. minor, the endemic flightless cormorant Nannopterum harrisi, and penguins Spheniscus mendiculus. The reasons why these colonies are, and will remain, a major tourist attraction are simple: they are close to the coast at convenient landing spots, an important point in an archipelago where it is usually difficult to get ashore and the terrain is often treacherous to cross; the birds are for the most part extremely tame, large, photogenic and colourful; and their behaviour is of interest to both the naturalist and the casual visitor.

The number of visitors is increasing steadily, and will probably reach the somewhat arbitrarily determined ceiling of 12,000 per year. Although tourism is carefully controlled by the Galapagos National Park Service, who restrict visitors to intelligently marked tourist trails, and each group is directed by a well-trained guide, there is concern for some of the more popular colonies. For example, the 100 -strong flightless cormorant colony at Punta Espinosa on Fernandina Island receives on average a boat-load of visitors per day, numbering from 8-90 people.

The impact of tourism can be monitored at two levels:

1. Checks can be made at the colonies at the beginning of the breeding season, and thereafter at suitable intervals, to quantify the rate of egg-laying, nest-density, hatching success and fledging success. The results are then compared with similar data from nearby unvisited colonies. This approach will certainly identify gross disturbances, but only after they have proceeded a long way. One cannot therefore be complacent at the finding of DeVries and 


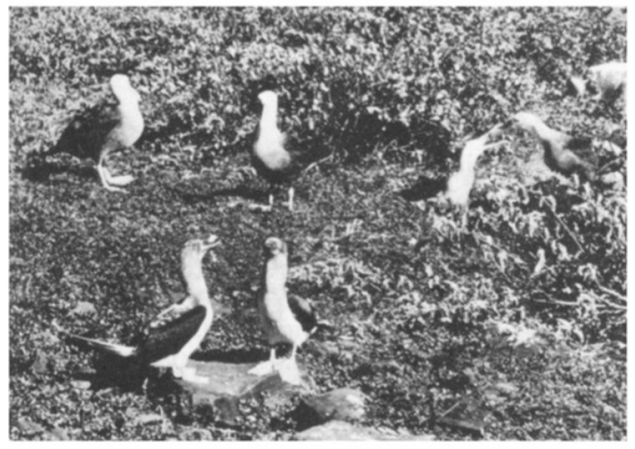

Blue-footed booby and waved albatross colony on Isla Española

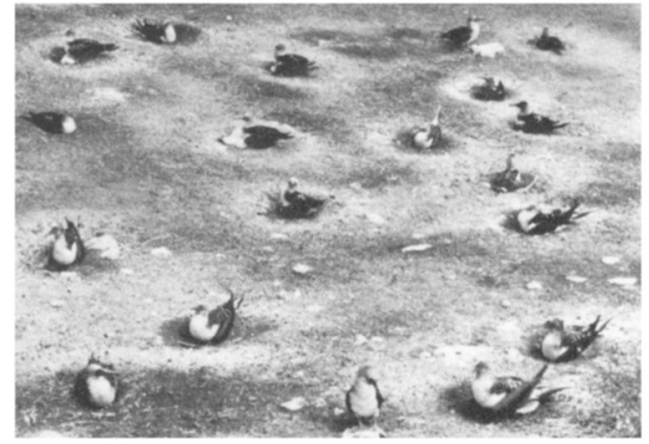

Blue-footed booby colony on Isabela

Harris, ${ }^{2}$ who, after three years of such monitoring, concluded that tourism was having very little direct effect on Galapagos sea-birds. Many of the indirect effects that they detected, for example the destruction by trampling of suitable nesting habitat for the magnificent frigate bird on North Seymour Island, have been eliminated by the introduction of tourist trails to which all visitors must keep. But a much finer level of monitoring is needed to identify incipient disturbance before irremediable damage has been done, and periodic checks may not be enough to detect such insidious effects as, for example, pair-bond rupturing, interrupted incubation and brooding rhythms and changed chickfeeding schedules.

2. In-depth studies of how the birds conduct their day-to-day lives are necessary in areas visited by tourists and, for comparison, in unvisited areas.

It is studies such as these, started by DeVries, that $\mathrm{I}$ have been making since 1976. They began on a small scale with both species of frigate bird, and have since been extended to the flightless cormorant, and both masked and redfooted boobies. An in-depth study of the waved albatross was started in 1978, and it is planned to include the blue-footed booby as well in 1979. These studies involve close observation of the bird colonies during all daylight hours, and at night when the moon permits, in order to quantify as much of the breeding behaviour as possible. Data on courtship behaviour, parental attendance at the colony, brooding, chick feeding and growth are collected and analysed, and statistical comparisons made between the visited and the unvisited colonies. It is then possible to identify the effects of tourist disturbance before they have drastic results, such as reduced breeding success or colony erosion. Implicit in the rationale for such studies is that tourist impact will be reflected in altered behaviour persisting long after the tourists have left.

These studies on the impact of tourists are proving an excellent medium for training advanced Ecuadorian students in field research and data analysis, supervised by a Research Station scientist. Some 20 students have been able to obtain thesis material, and the Charles Darwin Research Station is now in the forefront as a training institution in ecology, something very difficult otherwise to find in Ecuador. This has helped to foster a strong bond of co-operation between the CDRS and Ecuadorian universities. This cadre of young Galapagos-trained Ecuadorian scientists will prove invaluable as Ecuador takes increasing scientific responsibility for the islands.

In some species little is known about reproductive strategies and breeding behaviour, and differences arising between the tourist-visited and the control sites are difficult to interpret. For example, in the parts of the colony visited by 
tourists great frigate bird parents leave their chicks up to 30 days old unattended for longer periods, both day and night, than in the unvisited part, thus exposing them to heat trauma, marauding by other chick-stealing frigate birds, and predation by short-eared owls A sio flammeus. However, the tourist trail runs along the edge of the colony, and it is possible that peripherally nesting birds are less experienced, or 'less motivated' parents. This would require several years' study to elucidate. In flightless cormorants, the rate of fetching seaweed to the nest, a behaviour which is thought to have a paircementing function as well as being necessary for nest construction, is actually higher at the Punta Espinosa tourist colony than at a nearby control colony. But cormorant colonies are small, and one or two aberrant individuals may grossly bias the statistics. Furthermore, nothing is known of the variables which may affect seaweed-fetching, e.g. age of the fetcher, age of his mate, whether he has previously nested with the same mate.

We have now collected one whole year's data (i.e. all months) for the two frigate species, and it is reassuring that no changes unequivocally attributable to tourist disturbance can as yet be detected in either species of frigate, nor in the masked booby or the flightless cormorant, for each of which we have four months' data. But, as the above examples show, longer studies are needed, and only when the results are known will it be possible to interpret the true impact of tourism. Such studies help us to understand the reproductive strategies of the species and to detect at the very outset any detrimental effects of tourism; they also provide the necessary data for plans to regulate tourist traffic-e.g. which sites can be visited, how often, by how many people, etc. Meanwhile, long-term monitoring will continue in the hope of maintaining Galapagos, one of the most remarkable of sea-bird archipelagos, in its pristine condition.

\section{References}

1. COULSON, J. C. 1966. F. Anim. Ecol. 35: 268-279.

2. HARRIS, M. P., and Tj. DeVRIES 1976. Final report to WWF on evaluation of tourist impact and management.

3. LACK, D. 1966. Population studies of birds. Clarendon Press, Oxford.

4. WILSON, E. O. 1975. Sociobiology. Belknap Press (Harvard).

5. Von FRISCH, O. 1966. Zeitschrift fur Tierpsychologie 23, 1: 52-55, and 23, 4: 497500.

R. W. Tindle is Resident Scientist at the Charles Darwin Research Station; his research is aided by the Fauna Preservation Society and World Wildlife Fund.

\section{Madagascar's Wildlife}

A 52-page booklet about the wildlife of Madagascar designed to interest and inform foresters, village chiefs, teachers and school children has been produced by Anglia Television's 'Survival' programme in collaboration with the Malagasy Département des Eaux et Forêts. Maps and numerous photographs contributed by Tony and Liz Bomford include eleven of the endemic lemurs, some in good colour, and make this a most attractive publication of the sort that is much needed. It is urgently necessary to enlist the support and sympathy of the people if Madagascar's unique wildlife is to survive. This interesting and well illustrated booklet should make a splendid contribution to achieving this end for it appeals to the people on whom the burden of conservation finally falls, the villagers themselves.

Anglia Television has also given the Malagasy government copies of the three films the Bomfords shot in Madagascar together with a selection of other wildlife films, in order to promote interest in conservation in Madagascar. 